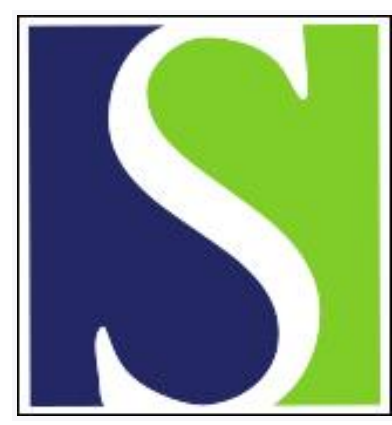

Scand J Work Environ Health 1992;18(5):310-316

https://doi.org/10.5271/sjweh.1571

Issue date: 01 Oct 1992

\section{Knee disorders in carpet and floor layers and painters.}

by Kivimaki J, Riihimaki $\mathrm{H}$, Hanninen $\mathrm{K}$

Affiliation: LEL Employment Pension Fund, Helsinki, Finland. 


\title{
Knee disorders in carpet and floor layers and painters
}

\author{
by Jorma Kivimäki, MD, ${ }^{1}$ Hilkka Riihimäki, MD, ${ }^{2}$ Kari Hänninen, $\mathrm{MSc}(\text { Eng })^{1}$
}

\begin{abstract}
KIVIMÄKI J, RIIHIMÄKI H, HÄNNINEN K. Knee disorders in carpet and floor layers and painters. Scand J Work Environ Health 1992;18:310-6. In an evaluation of the effect of kneeling work on the knees, 168 actively working carpet and floor layers and 146 house painters were examined with the aid of a questionnaire, a clinical examination, and radiography. Reported knee pain, knee accidents, and treatment regimens for the knees were more common among the carpet and floor layers than among the painters. Radiographic changes of the tibiofemoral joint were noted equally in the two occupational groups, but osteophytes of the patella were more common among the carpet and floor layers than among the painters. In a multivariate analysis, the determinants of osteophytosis of the knee were age, occupation, knee accidents, and smoking, and osteophytosis may be due to more frequent workbreaks from kneeling postures among smoking workers. This study indicates that kneeling work increases the risk of knee disorders and such radiographic changes that might be an initial sign of knee degeneration.
\end{abstract}

Key terms: knee arthrosis, kneeling, overuse injury, smoking, work-related disorders.

In their classic study among British miners, manual workers, and office workers, Kellgren \& Lawrence (1) verified the association between occupational load on the lower extremities and knee arthrosis. This association has been confirmed in several other studies in which knee arthrosis has been defined on the basis of tibiofemoral osteophytosis (2) or narrowing of tibiofemoral joint spaces (3).

In a comparison of different occupations, the incidence of knee pain increased when work required kneeling (4). In some occupations the proportion of kneeling postures is very high, and the work causes prolonged impact stresses against the patellar joint surfaces. These stresses are regarded as important in the genesis of arthrosis (5). In previous studies on occupational arthrosis, the effect of kneeling work on the patellofemoral joint has not been considered.

The objective of the present study was to evaluate the effect of occupational kneeling on the knees, with special interest in arthrosis.

\section{Subjects}

All of the actively working male carpet and floor layers who ranged in age from 25 to 49 years, lived in southern Finland, had at least five years of experience in their current occupation, and were registered members of the trade union were enlisted for this study. House

1 LEL Employment Pension Fund, Helsinki, Finland.

2 Institute of Occupational Health, Helsinki, Finland.

Reprint requests to: Dr J Kivimäki; Mantelikuja 3 A 5 , SF-01710 Vantaa, Finland. painters were selected with the same criteria with the use of frequency matching according to five-year age strata. One hundred and sixty-eight $(78 \%)$ of the 216 carpet and floor layers and $146(66 \%)$ of the 222 house painters participated in the study (table 1).

\section{Methods}

\section{Exposure assessment}

Eleven floor layers, fifteen carpet layers, and nine painters were videotaped performing typical work tasks. The videorecordings covered each task from the beginning to completion. The total observation time was $12 \mathrm{~h}$. In the analysis of the tapes, the durations of different work postures were registered, and the proportions of the total observation time were calculated for each of the following postures: standing, squatting with knees flexed more than 90 degrees, kneeling with one knee on the floor, and kneeling with both knees on the floor.

Table 1. The selection data.

\begin{tabular}{lcc}
\hline Source & $\begin{array}{c}\text { Carpet and } \\
\text { floor layers } \\
(\mathrm{N})\end{array}$ & $\begin{array}{c}\text { Painters } \\
(\mathbf{N})\end{array}$ \\
\hline Register of construction & & \\
worker union & 245 & 249 \\
$\quad$ Not active & 11 & 15 \\
Preliminary questionnaire & 234 & 234 \\
$\quad$ Not active & $18 \quad(8 \%)$ & $13 \quad(6 \%)$ \\
$\quad$ Nonrespondents & $11(5 \%)$ & $33(14 \%)$ \\
Invited & 205 & 188 \\
$\quad$ Nonrespondents & $37(18 \%)$ & $42(22 \%)$ \\
Participants & 168 & 146 \\
\hline
\end{tabular}




\section{Questionnaire data}

Individual factors. In a self-administered questionnaire, the subjects were asked to indicate their age, height, and weight. Body mass index (BMI) was calculated as weight (in kilograms) divided by height (in meters) squared, and three classes (BMI $<24.0$, $24.0-27.9$, and $>28.0$ ) were formed. The subjects were classified as smokers, ex-smokers, and nonsmokers according to their reported daily smoking habits. They reported the frequency of leisure-time physical exercise that lasted at least $20 \mathrm{~min}$ and caused sweating or breathlessness. For the data analysis, a dichotomous variable was formed (exercise less than once a week/exercise once a week or more). The number of years in the current occupation and the average number of workhours in a week were also reported.

Knee disorders. Life-time knee morbidity was evaluated from the responses to the questions on knee disorders that had been confirmed by a physician. Knee accidents were determined from the responses indicating whether they had ever had a knee injury treated by a physician or sudden and intense swelling of the knee. The subjects were also asked about life-time treatment regimens for the knee.

Knee pain. The presence of knee pain during the preceding month was evaluated from the responses to the question on whether or not the subjects experienced pain during the following tasks for the right and left knees separately: ascending stairs, descending stairs, walking on level ground, sitting still, resting at night, and squatting and kneeling. For further data analysis, a dichotomous knee pain index was formed based on the first five tasks $(0=$ no pain in any of the tasks; $\mathrm{I}=$ pain in one or several tasks). Pain in squatting and pain in kneeling were excluded from this categorization because of their differential occurrence in the two occupations. Acceptable evaluations of knee pain during the different tasks were received from 167 carpet and floor layers and 145 painters.

The subjects indicated the intensity of knee pain in the right and left knees during the preceding month on a $5-\mathrm{cm}$ long visual analogue scale ranging from "no pain" to "worst possible pain" according to Million et al (6). The ratings were approximated to the nearest centimeter.

Handicap due to knee pain. The handicap due to knee pain was evaluated on a $5-\mathrm{cm}$ long visual analogue scale ranging from "no handicap" to "total hindrance." The handicap in work and that in walking on level ground were recorded separately. For the analysis, the ratings were approximated to the nearest centimeter, ranging from 0 to 5 .

\section{Clinical examination}

One hundred and sixty-seven carpet and floor layers and 146 painters were clinically examined. The clinical examinations were carried out by a specialist in physical medicine who was unaware of each subject's medical history of knee disorders or actual knee symptoms. The examiner could not be blinded with regard to occupation because, in many cases, the skin changes at the anterior aspect of the knees revealed the subject's occupation. Knees were palpated to verify tenderness in the margins of the patella, in the medial and lateral margins of the tibiofemoral joint, and in the posterior aspect of the knee. Pain on grating of the patella, restrictions in passive motion, and pain at the end of a prompt passive extension was examined when the subject was lying supine with his thigh muscles relaxed.

A knee exertion test was performed as one part of the clinical examination. In this test, the subject was asked to squat 50 times in a free tempo without pauses. The squats had to be deep enough for the subject to touch the floor with his hands at the outer sides of his feet. Immediately after the test, the subjects were asked to estimate the intensity of pain in the right and left knees separately, on a 5-cm long visual analogue scale ranging from "no pain" to "worst imaginable pain." For the analysis, the ratings were approximated to the nearest centimeter.

\section{Radiographic examination}

A radiographic examination of the knees was accepted by 168 carpet and floor layers and 142 painters. An anteroposterior radiograph of the knees was taken on one film with the subject standing. For lateral projection the subject was lying on his side and the knee was slightly flexed. Tangential radiographs of the patellofemoral joint were taken with the subject lying supine, knees flexed 30 degrees, and the beam directed cephalad at an angle of 10 degrees from the surface on which the subject was lying (7).

The radiographic parameters determined were osteophytes and narrowing of joint spaces. Osteophytes were recorded for the following 10 anatomic locations: medial and lateral margins of the tibia, femur, and patella; medial and lateral eminentia, and upper and lower margins of the patellar joint surface. The size of an osteophyte was defined as the perpendicular distance from the cortex to the outer margin of the osteophytes. The knee was classified as arthrotic if any osteophytes were found in the inspected joint margins.

The radiographs were interpreted independently by two physicians (a radiologist and a physiatrist), who had no information about the occupation, age, or clinical data of the subjects. If their initial interpretations differed, they discussed the films and agreed on the final classification.

Both physicians reevaluated the radiographs of 50 patients. The two evaluations gave an equal osteophyte 
grading for $92 \%$ of the patellofemoral and $95 \%$ of the tibiofemoral joint margins.

\section{Ethical considerations}

Acceptance for the study protocol was obtained from an ethics committee, and the subjects were asked for an informed consent.

\section{Statistical methods}

The chi-square test was used for the statistical testing of contingency tables. In the multivariate analysis, binomial regression modeling was performed with GLIM (general linear interactive modeling) (8) with Wacholder's macros (9).

Rate ratio (RR) estimates and their $95 \%$ confidence intervals were calculated from the regression coefficients and their standard deviations. Osteophytosis of one or both knees was used as the dependent variable, and the independent variables were age, occupation, smoking, leisure-time physical exercise, body mass index, and reported knee accidents.

\section{Results}

\section{Exposure}

In the observed tasks of the carpet and floor layers, kneeling postures with one or both knees on the floor occurred approximately $42 \%$ of the total observation time, but among the painters kneeling postures were rare (figure 1). Postures with both knees on the floor were noted only for the carpet and floor layers. Squatting positions occurred in only $3 \%$ of the total observation time in both occupations.

\section{Individual characteristics}

The two occupational groups were similar in age, height, weight, and BMI (table 2). Thirteen percent of the carpet and floor layers and $22 \%$ of the painters were overweight (BMI greater than 28). The carpet and floor layers had worked in their present occupation for slightly less time than the painters. The average worktimes were 14.7 (SD 7.7) years and 18.1 (SD 7.5) years for the two groups, respectively. The average weekly worktime was $40 \mathrm{~h}$ for both occupations.

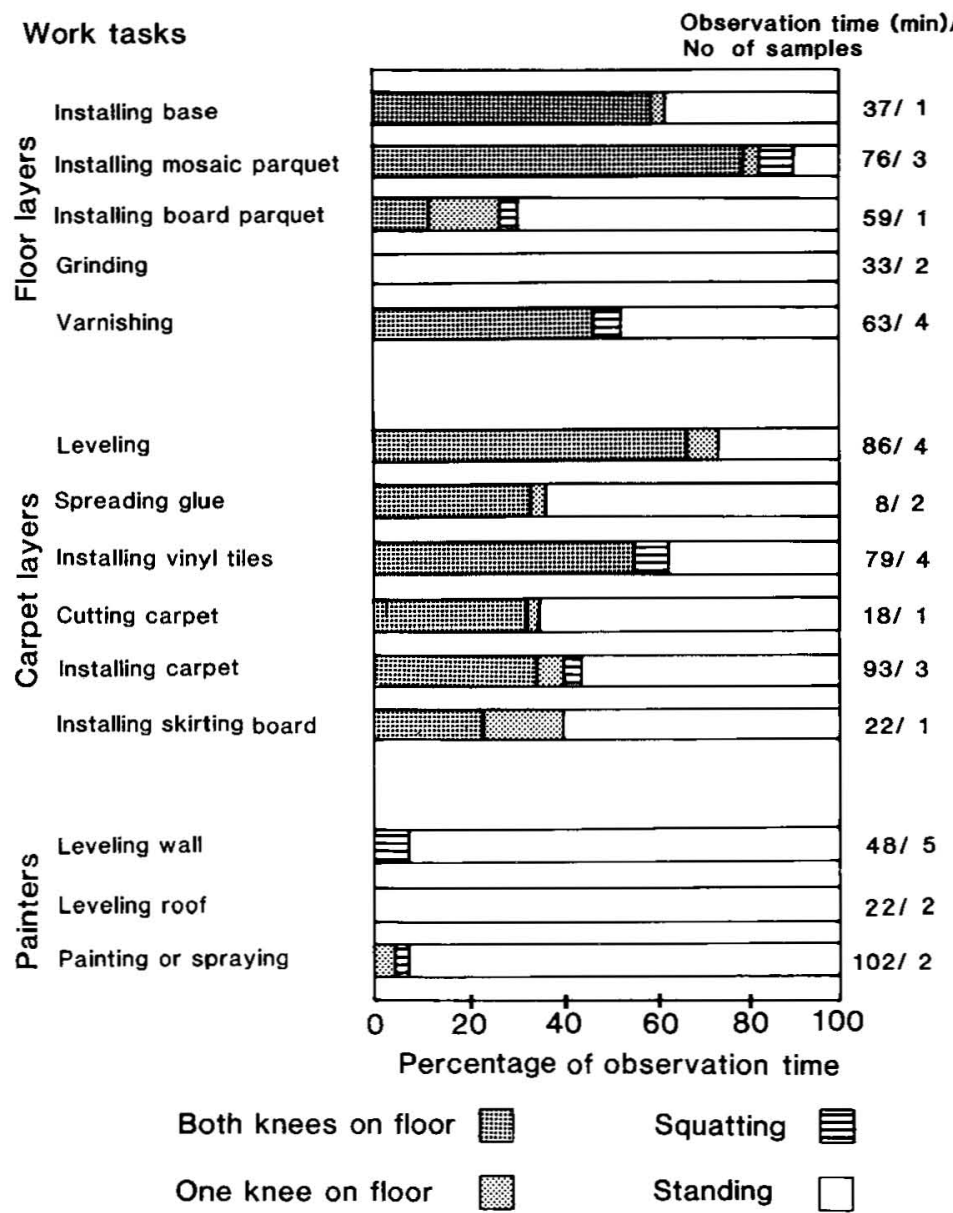

Figure 1. Knee postures according to work task and occupation. 
Table 2. Age and anthropometric data of the subjects. (BMI = body mass index)

\begin{tabular}{|c|c|c|c|c|c|c|c|c|}
\hline \multirow{2}{*}{ Group } & \multicolumn{2}{|c|}{ Age (years) } & \multicolumn{2}{|c|}{ Height (cm) } & \multicolumn{2}{|c|}{ Weight (kg) } & \multicolumn{2}{|c|}{ BMI $\left(\mathrm{kg} \cdot \mathrm{m}^{-2}\right)$} \\
\hline & Mean & SD & Mean & SD & Mean & SD & Mean & SD \\
\hline $\begin{array}{l}\text { Carpet and floor layers } \\
(\mathrm{N}=168)\end{array}$ & 38.5 & 6.8 & 176.8 & 5.8 & 78.5 & 10.3 & 25.1 & 2.8 \\
\hline Painters $(N=146)$ & 39.1 & 6.7 & 176.4 & 6.4 & 80.2 & 12.6 & 25.7 & 3.7 \\
\hline
\end{tabular}

Half of the subjects in both occupations were smokers, one-fourth had stopped smoking, and one-fourth had never smoked. The frequency of leisure-time physical exercise was reported equally in the groups, $41 \%$ of subjects having exercised at least once a week and $17 \%$ not having exercised at all.

\section{Knee disorders}

Meniscal lesions and ligament lesions were reported twice as frequently by the carpet and floor layers as by the painters, but a statistically significant difference between the two occupations was noted only for the reported frequency of knee bursitis (table 3). Fortysix percent of the carpet and floor layers and $27 \%$ of the painters had called a physician for knee accidents $(\mathrm{P}<0.001) ; 39$ versus $19 \%$, respectively, had been on sick leave for a knee accident $(\mathrm{P}<0.01)$; and 51 versus $26 \%$ had experienced a sudden swelling of the knee $(\mathrm{P}<0.001)$.

Minor treatment measures to the knees were reported more frequently by the carpet and floor layers, but for knee operations no difference between the groups was noted. Knee injections were reported by $18 \%$ of the carpet and floor layers and by $4 \%$ of the painters $P<0.001$ ), and the frequency of knee tapping was 34 and $11 \%$ in the groups, respectively $(P<0.001)$. Fourteen percent of the carpet and floor layers and $10 \%$ of the painters reported knee operations; $6 \%$ of the subjects in both groups had been operated on for meniscal lesions, and 1\% had been operated on for ligament ruptures.

\section{Symptoms}

Seventy-four percent of the carpet and floor layers and $61 \%$ of the painters reported knee pain for at least one of the seven tasks evaluated $(\mathrm{P}<0.05)$. For four tasks, the knee pain was reported significantly more frequently by the carpet and floor layers than by the painters, and the difference between the two occupations was greatest for the pain felt during kneeling (table 4). According to the knee pain index, $64 \%$ of the knees of the carpet and floor layers and $67 \%$ of those of the painters were painless.

The ratings from the visual analogue scales revealed that $34 \%$ of the carpet and floor layers and $53 \%$ of the painters had no pain in either knee $(P<0.01)$, and,
Table 3. Percentage of knee disorders verified by a physician among 168 carpet and floor layers and 146 painters.

\begin{tabular}{lcc}
\hline Disorder & $\begin{array}{c}\text { Carpet } \\
\text { and floor } \\
\text { layers } \\
(\%)\end{array}$ & $\begin{array}{c}\text { Painters } \\
(\%)\end{array}$ \\
\hline Arthrosis of the knee & 2 & 2 \\
Ruptures of knee menisces & 10 & 5 \\
Lesions in knee ligaments & 6 & 3 \\
Bursitis in front of the knee & 19 & $2 * * *$ \\
\hline$* * P<0.001$. & &
\end{tabular}

Table 4. Percentage of reported knee pain during different tasks in the preceding month among 167 carpet and floor and floor layers and 145 painters.

\begin{tabular}{lcc}
\hline Task & $\begin{array}{c}\text { Carpet and } \\
\text { floor layers } \\
(\%)\end{array}$ & $\begin{array}{c}\text { Painters } \\
(\%)\end{array}$ \\
\hline Ascending stairs & 25 & 24 \\
Descending stairs & 20 & 19 \\
Squatting & 40 & 39 \\
Walking on level ground & 23 & $14^{*}$ \\
Kneeling & 62 & $46^{* *}$ \\
Sitting still & 26 & $19^{*}$ \\
Resting at night & 23 & $12^{*}$ \\
\hline
\end{tabular}

${ }^{\star} P<0.05,{ }^{\star \star \star} P<0.001$.

respectively, ratings of $3-5$ were obtained on the visual analogue scale for 10 versus $4 \%$ of the subjects $(\mathrm{P}<0.05)$. Knee pain did not cause any trouble at work for $29 \%$ of the carpet and floor layers and $52 \%$ of the painters $(\mathrm{P}<0.001)$. Correspondingly, 44 and $67 \%$ $(\mathrm{P}<0.001)$ of the workers had no trouble with knee pain while walking on level ground.

\section{Clinical examination}

Soft tissue changes in the anterior aspect of the knee were the most typical findings among the carpet and floor layers. Clinical findings suggesting degeneration of the knee joint (ie, pain on grating of the patella, tenderness in the margins of the patella, and tenderness in the tibiofemoral joint margins) were noted equally in the two groups (table 5).

After the exertion test, "no pain" was indicated by $30 \%$ of the carpet and floor layers and $42 \%$ of the painters on the visual analogue scale $(P<0.01)$, and severe pain (values $3-5$ ) was indicated by 10 and $3 \%$, respectively $(\mathrm{P}<0.01)$. Seven percent of the subjects 
Table 5. Percentage of clinical findings in the knees of 167 carpet and floor layers and 146 painters.

\begin{tabular}{|c|c|c|}
\hline Clinical finding & $\begin{array}{c}\text { Carpet and } \\
\text { floor layers' } \\
\text { knees } \\
(\mathrm{N}=334) \\
(\%)\end{array}$ & $\begin{array}{c}\text { Painters' } \\
\text { knees } \\
(\mathrm{N}=292) \\
(\%)\end{array}$ \\
\hline $\begin{array}{l}\text { Tenderness in front of } \\
\text { the patellar tendon }\end{array}$ & 2 & 0 \\
\hline $\begin{array}{l}\text { Tenderness at the lower } \\
\text { pole of the patella }\end{array}$ & 5 & 3 \\
\hline $\begin{array}{l}\text { Skin thickening on the } \\
\text { front of the knee }\end{array}$ & 52 & $6^{* \star *}$ \\
\hline $\begin{array}{l}\text { Pain on grating of } \\
\text { the patella }\end{array}$ & 18 & 17 \\
\hline \multicolumn{3}{|l|}{$\begin{array}{l}\text { Tenderness on palpating } \\
\text { the patella }\end{array}$} \\
\hline $\begin{array}{l}\text { Medially } \\
\text { Laterally }\end{array}$ & $\begin{array}{l}5 \\
2\end{array}$ & $\begin{array}{l}7 \\
1\end{array}$ \\
\hline $\begin{array}{l}\text { Crepitation of the } \\
\text { patella }\end{array}$ & 15 & 14 \\
\hline \multicolumn{3}{|l|}{$\begin{array}{l}\text { Tenderness in the } \\
\text { tibiofemoral joint }\end{array}$} \\
\hline $\begin{array}{l}\text { Medial joint margin } \\
\text { Lateral joint margin }\end{array}$ & $\begin{array}{l}8 \\
2\end{array}$ & $\begin{array}{l}6 \\
1\end{array}$ \\
\hline $\begin{array}{l}\text { Pain at the end of prompt } \\
\text { passive extension }\end{array}$ & 10 & 9 \\
\hline
\end{tabular}

$\star \star * * P<0.001$.

Table 6. Percentage of osteophytes according to location in the knees of 168 carpet and floor layers and 142 painters.

\begin{tabular}{lcc}
\hline Location & $\begin{array}{c}\text { Carpet and } \\
\text { floor layers' } \\
\text { knees } \\
(\mathrm{N}=336) \\
(\%)\end{array}$ & $\begin{array}{c}\text { Painters' } \\
\text { knees } \\
(\mathrm{N}=284) \\
(\%)\end{array}$ \\
\hline $\begin{array}{l}\text { Margins of the patellar } \\
\text { joint surface }\end{array}$ & & \\
Cranial & 35 & $28^{* *}$ \\
Caudal & 26 & $11^{*}$ \\
Medial & 4 & 4 \\
Lateral & 15 & 20 \\
Eminentia & & \\
$\quad$ Medial & 11 & 12 \\
Lateral & 12 & 11 \\
Margins of tibiofemoral & & \\
joint spaces & & 20 \\
Tibia medial & 18 & 2 \\
Femur medial & 4 & 3 \\
Tibia lateral & 7 & \\
Femur lateral & 7 & \\
\hline * P<0.05, * $P<0.01$. & &
\end{tabular}

(8 carpet and floor layers and 12 painters) had to interrupt the exertion test due to breathlessness or weakness in the legs.

\section{Radiographic examination}

Narrowing of the patellofemoral joint space was evident in $1 \%$, and narrowing of the medial tibiofemoral joint space in $\mathbf{2 \%}$, of the radiographs. The prevalence of knee osteophytes was $58 \%$ among the carpet and floor layers and $41 \%$ among the painters $(\mathrm{P}<0.01)$. Osteophytes were located the most often in the cranial and caudal margins of the patellar joint surface, and in these locations they were significantly more common among the carpet and floor layers than among the painters (table 6). Osteophytes were equally prevalent in the tibiofemoral joint in the two groups. The prevalence of patellar osteophytes increased with age in both occupations, and in every age group osteophytes were more common among the carpet and floor layers than among the painters (figure 2).

The osteophytes were usually very small, and only $7 \%$ of them had a perpendicular distance of $2 \mathrm{~mm}$ from the cortex to the outer margin of the osteophyte.

In the multivariate analysis, age, reported knee accidents, occupation, and current smoking were significant variables associated with osteophytosis of the knees (table 7). Leisure-time physical exercise and the BMI were included in the analysis, but they did not have a significant effect on the occurrence of knee arthrosis. The rate ratio for knee arthrosis in $81 \mathrm{ex}-$ smokers was 1.0 in relation to the occurrence in 65 nonsmokers, and these groups were combined in the analysis.

Osteophytosis of the knee was related to the knee pain index of the carpet and floor layers (RR 1.4, 95\% CI 1.0-2.0) but not to that of the painters (RR 1.1, 95\% CI $0.7-1.6$ ).

Pain on grating of the patella or tenderness in the patellar margins was not related to patellar osteophytosis. The ratings on the visual analogue scale in relation to the exertion tasks (values $1-5$ ) were associated with osteophytosis in both occupations. Pain was reported in $59 \%$ of the knees without patellar osteophytes and in $71 \%$ of the knees with patellar osteophytes $(\mathrm{P}<0.01)$.

\section{Discussion}

This comparison of two occupations from the house building trade revealed that knee disorders, knee symptoms, and radiographic changes of the patella were more common among the carpet and floor layers than among the painters. The radiographic changes at the margins of the patellar joint surface were related to knee symptoms, but not to clinical findings of the patellofemoral joint.

It is probable that primary and secondary selection would tend to dilute the effect of occupational load in this study. Higher knee load requirements would tend to select men with knee disorders from work as a carpet or floor layer. The restriction of the study subjects to those less than 50 years of age was used to diminish the effect of possible differential secondary selection due to knee disorders.

The carpet and floor layers participated in the examinations more frequently than the painters, and it 
Figure 2. Prevalence of patellar osteophytosis in the knees of 168 carpet and floor layers and 142 painters by age and occupation.

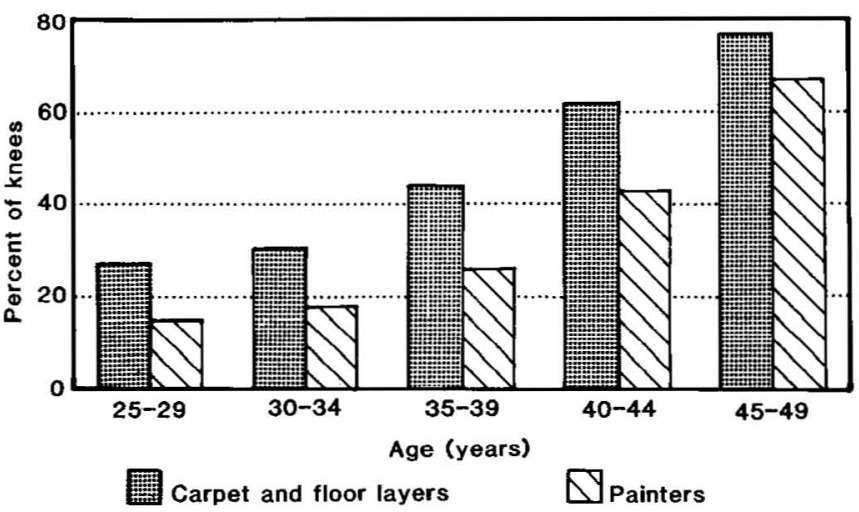

is possible that workers with knee problems were more willing to have their knees examined. We received a reply to the questionnaire from about one-half of the workers who had not accepted the invitation to participate in this study. Most of these workers were not experiencing any knee problems and, for this reason, regarded the examinations as unnecessary. This occurrence may have caused a positive bias.

The work analysis confirmed that knee load is essentially different in the two occupational groups. The carpet and floor layers kneeled, on the average $42 \%$ of the time in the observed work tasks. An even greater proportion of kneeling postures has been reported by carpet installers in the United States, where a tool called a "knee kicker" is also used (10). This type of tool is not used in Finland.

Although the knee symptoms were associated with occupation, only small differences were noted in the reported knee disorders and the current clinical findings between the two groups. Skin changes and bursitis in the anterior aspect of the knee seemed to be the most typical lesions of carpet and floor layers, and this finding is well in concordance with previous knowledge $(11,12)$. Meniscal ruptures, knee ligament injuries, and arthrographies of the knees were reported more often by the carpet and floor layers than by the painters, but the differences were not significant. It is rather surprising that, in spite of the great differences in occupational knee load, tenderness of the patella and the patellar tendon were identified equally often in both occupational groups.

Most of the subjects had started their present occupation in their 20ies. Thus, the possible effect of work load on early radiographic changes might be seen at least in the oldest age groups, although severe arthrotic changes are not very probable in the age range of the subjects. Patellar osteophytosis seems to be a finding worth noting because it had a significant association with pain in the knee exertion test. The determinants of osteophytosis (age, occupation, knee accidents) have been acknowledged earlier as risk indicators of knee arthrosis (13). Osteophytes are usually regarded as a sign of joint degeneration, although they are not al-
Table 7. Rate ratios and $95 \%$ confidence intervals for the determinants of knee arthrosis in a multivariate binomial regression analysis.

\begin{tabular}{lcc}
\hline Determinant & Rate ratio & $\begin{array}{c}95 \% \\
\text { confidence } \\
\text { interval }\end{array}$ \\
\hline Occupation & 1.4 & $1.1-1.7$ \\
Knee accidents & 1.5 & $1.2-1.8$ \\
Smoking & & \\
$\quad$ Nonsmokers and ex-smokers & 1.0 & \\
Current smokers & 0.8 & $0.6-0.9$ \\
Age (years) & & \\
$25-34$ & 1.0 & \\
$35-39$ & 1.4 & $1.0-2.0$ \\
$40-44$ & 2.0 & $1.4-2.7$ \\
$45-49$ & 2.0 & $1.4-2.7$ \\
\hline
\end{tabular}

ways accompanied by lesions of the cartilage (14) and they do not necessarily precede other radiographic findings of arthrosis (15). The different relationship between the knee pain index and radiographic changes in the two occupations suggests that the load in carpet and floor layers' work may provoke symptoms in arthrotic knees.

Smoking had a negative correlation with knee arthrosis, and the same phenomenon has been described in a previous epidemiologic study (2). The reason for this association remains obscure. One could speculate that smoking workers take breaks more frequently and thus shorten the duration of continuous exposure to knee loads.

Examinations with arthroscopy and scintigraphy have shown that, in its early stages, arthrosis can cause many changes in bone metabolism and cartilage before becoming visible in radiography (16). The low sensitivity of the radiographic examination may partially account for the poor correlations between radiographic findings and knee pain. On the other hand, knee pain in subjects aged $25-49$ years is more likely caused by factors other than arthrosis (eg, meniscal lesions, chondromalacia of the patella, and soft-tissue overuse syndromes). 
In this study knee morbidity and osteophytosis of the knees were related to occupation. Our results indicate that long-term kneeling work provokes knee symptoms and contributes to the development of knee arthrosis.

\section{Acknowledgments}

This study was financially supported by the Finnish Work Environment Fund.

\section{References}

1. Kellgren JH, Lawrence JS. Rheumatism in miners: part II. X-ray study. Br J Ind Med 1952;9:197-207.

2. Andersson JJ, Felson DT. Factors associated with osteoarthritis of the knee in the first national health and nutrition examination survey (HANES I). Am J Epidemiol 1988;128:179-89.

3. Lindberg H, Montgomery F. Heavy labor and the occurrence of gonarthrosis. Clin Orthop 1987;214:235-6.

4. Ekström $\mathbf{H}$, Engholm G, Nyqvist B, Wallenquist $\mathbf{A}$. Knäbesvär som arbetsmedicinskt problem [Knee pain as a problem of the occupational medicine]. Stockholm: Bygghalsans forskningsstiftelse, 1983.

5. Anderson JAD. Arthrosis and its relation to work. Scand J Work Environ Health 1984;10:429-33.

6. Million R, Hall W, Nilsen KH, Baker RD, Jayson MIV. Assessment of the progress of the back-pain patient.
Spine 1982;7:204-12.

7. Laurin CA, Dussault R, Levesque HP. The tangential $\mathrm{X}$-ray investigation of the patellofemoral joint. Clin Orthop 1979;144:16-26.

8. Numerical Algorithms Group. The GLIM system: release 3.77 manual, Royal Statistical Society. Oxford (England): Numerical Algorithms Group, 1985.

9. Wacholder S. Binomial regression in GLIM: estimating risk ratios and risk differences. Am J Epidemiol 1986; 123:174-84.

10. Bhattacharya A, Mueller M, Putz-Anderson V. Traumatogenic factors affecting the knees of carpet installers. Appl Ergon 1985;16:243-50.

11. Tanaka S, Halperin WE, Smith AB, Lee ST, Luggen ME, Hess EV. Skin effects of occupational kneeling. Am J Ind Med 1985;8:341-9.

12. Smillie IS. Affections of the synovial membrane: local. In: Smillie IS, ed. Diseases of the knee joint. Edinburgh: Churchill Livingstone, 1974:140-62.

13. Felson DT. Epidemiology of hip and knee osteoarthritis. Epidemiol Rev 1988;10:1-28.

14. Alexander CJ. Osteoarthritis: a review of old myths and current concepts. Skeletal Radiol 1990;19:327-33.

15. Hernborg J, Nilsson BE. The relationship between osteophytes in the knee joint, osteoarthritis and aging. Acta Orthop Scand 1973;44:69-74.

16. Collier BD, Johnson RP, Carrera GF, Isitsan AT, Veluvolu P, Knobel J, et al. Chronic knee pain assessed by SPECT: comparison with other modalities. Radiology $1985 ; 157: 795-802$.

Received for publication: 13 November 1991 